CEMENTITIOUS BARRIERS PARTNERSHIP FY13 MID-YEAR REPORT 


\title{
CEMENTITIOUS BARRIERS PARTNERSHIP FY13 MID-YEAR REPORT
}

\author{
H.H. Burns, G.P. Flach, C. A. Langton \\ Savannah River National Laboratory \\ Savannah River Site \\ Aiken, South Carolina 29808 \\ D. S. Kosson \\ K. G. Brown \\ Vanderbilt University, School of Engineering \\ Consortium for Risk Evaluation with Stakeholder Participation III \\ Nashville, TN 37235 \\ E. Samson \\ SIMCO Technologies, Inc. \\ 1400 Boul Parc-Technologique \\ Quebec, Canada \\ J. C. L. Meeussen \\ Nuclear Research and Consultancy Group (NRG) \\ Petten, The Netherlands \\ H. A. van der Sloot \\ Hans van der Sloot Consultancy \\ Langedijk, The Netherlands \\ E. J. Garboczi \\ Materials \& Construction Research Division \\ National Institute of Standards and Technology \\ Gaithersburg, MD 20899
}

May 2013

CBP-TR-2013-01, Rev. 0 


\section{ACKNOWLEDGEMENTS}

This report was prepared for the United States Department of Energy under Interagency Agreement No. DE-AI09-09SR22667 and is an account of work performed under that contract. This report was also prepared with the financial support by the U. S. Department of Energy, under Cooperative Agreement Number DE-FC01-06EW07053 entitled 'The Consortium for Risk Evaluation with Stakeholder Participation III' awarded to Vanderbilt University. Reference herein to any specific commercial product, process, or service by trademark, name, manufacturer, or otherwise does not necessarily constitute or imply endorsement, recommendation, or favoring of same by Savannah River Nuclear Solutions, Vanderbilt University or by the United States Government or any agency thereof. The views and opinions of the authors expressed herein do not necessarily state or reflect those of the United States Government or any agency thereof. This report is part of a larger multi-investigator project supported by the U. S. Department of Energy entitled the Cementitious Barriers Partnership. The opinions, findings, conclusions, or recommendations expressed herein are those of the authors and do not necessarily represent the views of the U.S. Department of Energy. This work was also partially supported by the National Institute of Standards and Technology Sustainable, High Performance Infrastructure Materials program.

\section{DISCLAIMER}

This work was prepared under an agreement with and funded by the U. S. Government. Neither the U.S. Government or its employees, nor any of its contractors, subcontractors or their employees, makes any express or implied: 1. warranty or assumes any legal liability for the accuracy, completeness, or for the use or results of such use of any information, product, or process disclosed; or 2. representation that such use or results of such use would not infringe privately owned rights; or 3. endorsement or recommendation of any specifically identified commercial product, process, or service. Any views and opinions of authors expressed in this work do not necessarily state or reflect those of the United States Government, or its contractors, or subcontractors.

\section{Printed in the United States of America United States Department of Energy Office of Environmental Management Washington, DC}

This document is available on the U.S. DOE Information Bridge and on the CBP website: http://cementbarriers.org/

An electronic copy of this document is also available through links on the following website: http://srnl.doe.gov/ 


\section{FOREWORD}

The Cementitious Barriers Partnership (CBP) Project is a multi-disciplinary, multi-institutional collaboration supported by the United States Department of Energy (US DOE) Office of Waste Processing. The objective of the CBP project is to develop a set of tools to improve understanding and prediction of the long-term structural, hydraulic, and chemical performance of cementitious barriers used in nuclear applications.

A multi-disciplinary partnership of federal, academic, private sector, and international expertise has been formed to accomplish the project objective. In addition to the US DOE, the CBP partners are the Savannah River National Laboratory (SRNL), Vanderbilt University (VU) / Consortium for Risk Evaluation with Stakeholder Participation (CRESP), Energy Research Center of the Netherlands (ECN), and SIMCO Technologies, Inc. The Nuclear Regulatory Commission (NRC) is providing support under a Memorandum of Understanding. The National Institute of Standards and Technology (NIST) is providing research under an Interagency Agreement. Neither the NRC nor NIST are signatories to the CRADA. The periods of cementitious performance being evaluated are up to and $>100$ years for operating facilities and $>1000$ years for waste management. The set of simulation tools and data developed under this project will be used to evaluate and predict the behavior of cementitious barriers used in near-surface engineered waste disposal systems, e.g., wasteforms, containment structures, entombments, and environmental remediation, including decontamination and decommissioning analysis of structural concrete components of nuclear facilities (spent-fuel pools, dry spent-fuel storage units, and recycling facilities such as fuel fabrication, separations processes). Simulation parameters will be obtained from prior literature and will be experimentally measured under this project, as necessary, to demonstrate application of the simulation tools for three prototype applications (wasteform in concrete vault, high-level waste tank grouting, and spent-fuel pool). Test methods and data needs to support use of the simulation tools for future applications will be defined.

The CBP project is a multi-year effort focused on reducing the uncertainties of current methodologies for assessing cementitious barrier performance and increasing the consistency and transparency of the assessment process. The results of this project will enable improved risk-informed, performance-based decision-making and support several of the strategic initiatives in the DOE Office of Environmental Management Engineering \& Technology Roadmap. Those strategic initiatives include 1) enhanced tank closure processes; 2) enhanced stabilization technologies; 3 ) advanced predictive capabilities; 4) enhanced remediation methods; 5) adapted technologies for site-specific and complex-wide D\&D applications; 6) improved SNF storage, stabilization and disposal preparation; 7) enhanced storage, monitoring and stabilization systems; and 8) enhanced long-term performance evaluation and monitoring. 


\section{Cementitious Barriers Partnership}

\section{FY13 Mid-Year Report}

\section{Summary}

In FY2013, the Cementitious Barriers Partnership (CBP) is continuing in its effort to develop and enhance software tools demonstrating tangible progress toward fulfilling the objective of developing a set of tools to improve understanding and prediction of the long-term structural, hydraulic and chemical performance of cementitious barriers used in nuclear applications. In FY2012, the CBP released the initial inhouse "Beta-version" of the CBP Software Toolbox, a suite of software for simulating reactive transport in cementitious materials and important degradation phenomena. The current primary software components are LeachXS/ORCHESTRA, STADIUM, and a GoldSim interface for probabilistic analysis of selected degradation scenarios as shown in Figure 1. THAMES is a planned future CBP Toolbox component (FY13/14) focused on simulation of the microstructure of cementitious materials and calculation of resultant hydraulic and constituent mass transfer parameters needed in modeling.

This past November, the CBP Software Toolbox Version 1.0 was released that supports analysis of external sulfate attack (including damage mechanics), carbonation, and primary constituent leaching. The LeachXS component embodies an extensive material property measurements database along with chemical speciation and reactive mass transport simulation cases with emphasis on leaching of major, trace and radionuclide constituents from cementitious materials used in DOE facilities, such as Saltstone (Savannah River) and Cast Stone (Hanford), tank closure grouts, and barrier concretes. STADIUM focuses on the physical and structural service life of materials and components based on chemical speciation and reactive mass transport of major cement constituents and aggressive species (e.g., chloride, sulfate, etc.).

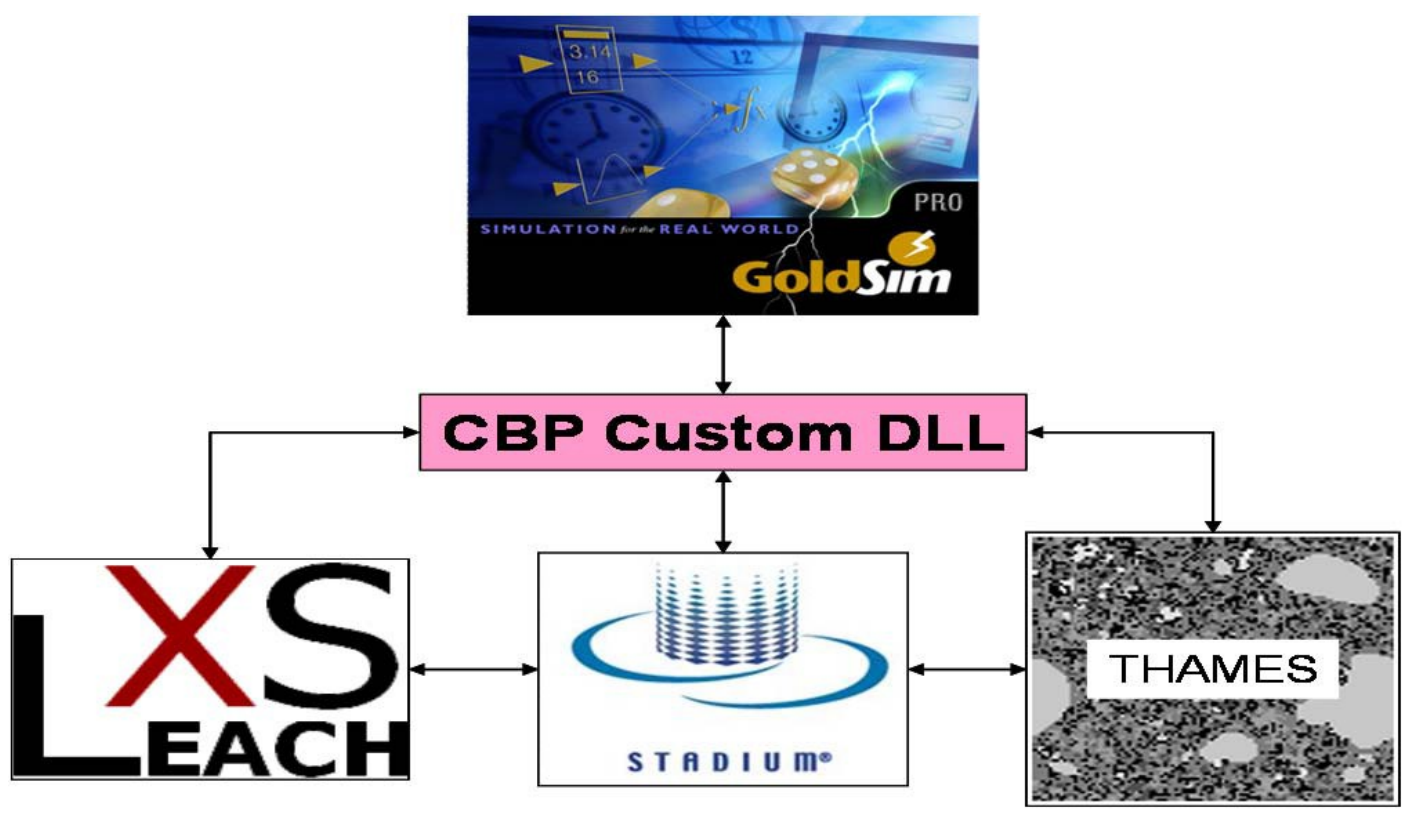

Figure 1. CBP Software Toolbox 
The CBP issued numerous reports and other documentation that accompanied the "Version 1.0" release including a CBP Software Toolbox User Guide and Installation Guide. These documents, as well as, the presentations from the CBP Software Toolbox Demonstration and User Workshop, which are briefly described below, can be accessed from the CBP webpage at http://cementbarriers.org/. The website was recently modified to describe the CBP Software Toolbox and includes an interest form for application to use the software.

The CBP FY13 program is continuing research to improve and enhance the simulation tools as well as develop new tools that model other key degradation phenomena not addressed in Version 1.0. Also efforts to continue to verify the various simulation tools thru laboratory experiments and analysis of field specimens are ongoing to quantify and reduce the uncertainty associated with performance assessments are ongoing. This mid-year report also includes both a summary on the FY13 software accomplishments in addition to the release of Version 1.0 of the CBP Software Toolbox and the various experimental programs that are providing data for calibration and validation of the CBP developed software. The focus this year for experimental studies was to measure transport in cementitious material by utilization of a leaching method and reduction capacity of saltstone field samples. Results are being used to calibrate and validate the updated carbonation model.

\section{FY13 CBP Software Development}

The CBP Software Toolbox, Version 1.0 has produced tangible benefits to the DOE Performance Assessment (PA) community. A review of prior DOE PAs has provided a list of potential opportunities for improving cementitious barrier predictions through the use of CBP Software tools. These opportunities include:

1) Impact of atmospheric exposure to concrete and grout before closure, such as accelerated slag and Tc-99 oxidation,

2) Prediction of changes in $\mathrm{Kd} /$ mobility as a function of time that result from changing $\mathrm{pH}$ and redox conditions,

3) Concrete degradation from rebar corrosion due to carbonation,

4) Early age cracking from drying and/or thermal shrinkage, and

5) Degradation due to sulfate attack.

The CBP has already had opportunity to provide near-term, tangible support to ongoing DOE-EM PAs such as the Savannah River Saltstone Disposal Facility (SDF) by providing a sulfate attack analysis that predicts the extent and damage that sulfate ingress will have on the concrete vaults over extended time (i.e., > 1000 years). This analysis is one of the many technical opportunities in cementitious barrier performance that can be addressed by the DOE-EM sponsored CBP software tools. 
CBP Software Toolbox Analysis of Saltstone Disposal Facility

\section{CBP Toolbox Version 1.1 Code Integration Enhancements}

In FY2013, enhancements were made to the CBP Software Toolbox Version 1.0, specifically the code integration functionality aspects of the Toolbox. The most significant enhancements are:

1) Improved graphical display of model results - The CBP Software Toolbox has been modified with improved methods for displaying results including two and three-dimensional plots of model results.

2) Improved error analysis and reporting - The CBP developed a custom Dynamic Link Library (DLL) to enable data communication between the Toolbox software components, allowing comparative analysis. Error messages have been enhanced to more clearly explain problems encountered during execution of the DLL instruction files. Additional information will allow the user to quickly identify the problem and take corrective actions promptly.

3) Increase in the default maximum model mesh size from 301 to 501 nodes - Modifications of increasing the mesh size provides a finer resolution which is necessary with operation of STADIUM which includes several layers within the model. The finer resolution will improve the distinctions between the layers.

4) The ability to set the LeachXS/Orchestra (LXO) degradation simulation time frames through the GoldSim interface - The original version of the CBP Software Toolbox did not allow the User to change the degradation simulation time of the cementitious barrier. Now the Goldsim User Interface (GUI) has been modified for LXO so that the User can determine the time frames desired or dictated by the performance assessment.

\section{CBP Dual Regime Module Development}

In FY2013, a reactive transport model was developed as part of the CBP to simulate the release of radionuclides from grout and to estimate the evolution of $\mathrm{pH}$. In tank closure, as well as, any cementitious closure facility that uses grout to stabilize radionuclide species, the grout can be assumed to have varying extents of cracking. The partially or completely degraded grouted tank is idealized as a dual regime system comprising of a mobile region with cracks and macropores, and an immobile/ stagnant region comprising of the solid matrix with micropores. The transport profiles of the species are calculated by incorporating advection of species through the mobile region, diffusion of species through the immobile/stagnant region, and exchange of species between the mobile and immobile regions. The dual regime reactive transport model predictions have been calibrated with experimental release data from an up-flow column percolation test. The coupled reactive transport model can be used to support the PA process for evaluating potential risks from leaching of a cracked grouted tank or vault such as at the Saltstone Disposal Facility. 


\section{CBP Oxidation Module Development}

In FY2013 the CBP began development of a Toolbox module for simulating slag/Tc oxidation via oxygen transport in both the liquid and gas phases. This module is being developed to address a very important phenomenon: the retention of Tc-99 in slag-bearing cementitious waste forms and barriers. Ground furnace slag is included in the waste grout and concrete barrier dry mixes to create reducing conditions and effectively immobilize Tc-99 as Tc(IV). This module is being calibrated using SRNL experimental data from the oxidation and reduction capacity report discussed in the experimental section of this report. The module is anticipated to be ready for demonstration in FY2014.

\section{CBP Fracture Properties and Fracture Flow Module Development}

Recognizing that physical damage to cementitious materials typically occurs in the form of cracking, ongoing CBP development efforts are also focused on predicting damage through fracture mechanics considerations, determining the hydraulic and transport properties of fractured materials, and implementing corresponding Toolbox simulation capabilities. In early FY2013, the CBP funded the method development for determining the hydraulic conductivity of fractured materials.

\section{FY2013 CBP Experimental Programs}

CBP experimental efforts to date have focused on external sulfate attack, carbonation, and primary constituent leaching phenomena. In FY2013, the experimental program focus at SRNL is:

- Method development to measure the progress of the oxidation front the impacts the retention of redox sensitive radionuclides such as Tc-99,

- Development of methods to measure hydraulic and transport properties of fractured materials,

- Determination of the initial mineral phases of the saltstone and concrete barriers which has been determined by the CBP as significantly impacting the modeling results depending on the mineral assemblage.

\section{Measurement of the Oxidation Front Progress and Reduction Capacity of Cementitious Waste Forms} Documented in: "Effect Of Oxidation on Chromium Leaching And Redox Capacity Of Slag-Containing Waste Forms" SRNL, P. M. Almond, D. B. Stefanko, and C. A. Langton, 2013.

The rate of oxidation is important to the long-term performance of waste forms that contain redox sensitive contaminants (i.e., solubilities are a function of the oxidation state) such as technetium. The rate of oxidation front advancement into a monolith and the effect of oxygen ingress on redox sensitive contaminants are needed to:

1) Develop the conceptual model for performance predictions,

2) Provide data to parameterize fate and transport models, and

3) Validate computational codes.

Several U.S. DOE sites use waste forms and concrete containment structures for radioactive waste disposal 
that are designed to have a chemically reducing environment to immobilize selected contaminants such as $\mathrm{Tc}(\mathrm{VII})$ and $\mathrm{Cr}(\mathrm{VI})$. These waste forms and containment structures are typically deployed in near surface unsaturated oxidizing environments. Consequently, the effect of exposure to air (oxygen) and water containing dissolved oxygen during production, during the period of institutional control, and over the long term period of performance is important for predicting the speciation and mobility of the redox sensitive radioactive and stable contaminants.

Tc in the salt solution is reduced to Tc(IV) has been shown to react with ingredients in the waste form to precipitate a low solubility sulfide compound. Upon exposure to oxygen, the compounds containing Tc(IV) oxidize to form pertechnetate ion $\left(\mathrm{TcO}_{4}{ }^{-}\right)$which is very soluble. Consequently the rate of Tc oxidation front advancement into a monolith and the Tc leaching profile as a function of depth from an exposed surface are important to waste form performance and ground water concentration predictions.

Depth discrete sampling of materials exposed to realistic conditions in combination with short term leaching of crushed samples has potential for advancing the understanding of factors influencing performance and will support conceptual model development.

In FY13, an experimental program for measuring contaminant oxidation rate based on leaching of select contaminants of concern has been conducted and documented in XXXX. In addition, the relationship between reduction capacity and contaminant oxidation is addressed. Chromate was used as a nonradioactive surrogate for pertechnetate in simulated waste form samples. Depth discrete subsamples were cut from material exposed for to SRS "field cured" conditions. The subsamples were prepared and analyzed for both reduction capacity and $\mathrm{Cr}$ leachability.

The objective of this study was to provide information for developing a conceptual model for redoxcontrolled contaminant release from cementititous waste forms. Specific lines of investigation include:

1) Evaluate leaching of depth discrete subsamples of a reducing salt waste form exposed to field conditions, i.e., top surface of the sample exposed to air in a closed container at the SRS Z-Area.

2) Determine the relationship between the Angus and Glasser Reduction Capacity Measurement, i.e, ability of a slag containing waste form to reduce cerium, and leachability of depth descrete subsamples for:

a. A redox sensitive contaminant, $\mathrm{Cr}(\mathrm{VI}) / \mathrm{Cr}(\mathrm{III})$, for a waste form cured under SRS "field conditions".

b. Non redox sensitive contaminants, $\mathrm{Na}$, and $\mathrm{NO}_{3}{ }^{-}$.

3) Evaluate the effect of exposure time to air on leachability of $\mathrm{Cr}$ in depth discrete subsamples.

4) Evaluate the effect of leaching time $18 \mathrm{hr}$ versus 28 day for crushed depth discrete subsamples.

Results from field-cured samples indicate that the depth at which leachable $\mathrm{Cr}$ was detected advanced further into the sample exposed for 302 days compared to the sample exposed to air for 118 days (at least $50 \mathrm{~mm}$ compared to at least $20 \mathrm{~mm}$ ).

Reduction capacity measurements performed on depth discrete samples could not be correlated with the amount or $\mathrm{Cr}$ leached from depth discrete subsamples or with the oxidation front. Consequently, this method for determining reduction capacity may not be a good indicator of the effective contaminant 
oxidation rate in a relatively porous solid ( 40 to 60 volume percent porosity). The $\mathrm{Cr}$ extracted in depth discrete samples ranged from a maximum of about $5.8 \%$ at about $5 \mathrm{~mm}$ (118 day exposure) to about $4 \%$ at about $10 \mathrm{~mm}$ (302 day exposure).

The carbonation front was also estimated to have advanced to at least $28 \mathrm{~mm}$ in 302 days based on visual observation of gas evolution during acid addition during the reduction capacity measurements.

Depth discrete sampling of materials exposed to realistic conditions in combination with short term leaching of crushed samples has potential for advancing the understanding of factors influencing performance and will support conceptual model development.

\section{Method Development for Measuring Transport Properties in Fractured Materials}

The hydraulic properties, primarily unsaturated hydraulic conductivity/permeability, of damaged (fractured) saltstone and concrete have not been measured. Plausible, but invalidated, theoretical model constructs for unsaturated hydraulic conductivity are currently used in PA modeling for cracked saltstone and concrete. The objective of this program is to advance PA model support by developing an experimental method for measuring the hydraulic conductivity of fractured cementitious materials under unsaturated conditions, and applying the technique to fractured cementitious samples. In FY12, to enable method development for permeability measurements, data was collected from a synthetic fracture and impermeable matrix (i.e., stacked glass plates on edge). This data will later be used in modeling to develop/validate a fractured flow model.

Tests were performed on samples damaged as a result of exposure to aggressive contact solutions to estimate their tortuosity. The tortuosity was evaluated on the basis of the migration test developed by SIMCO and adopted by the U.S. Navy as part of their concrete testing program. Results so far have shown that compared to an undamaged reference sample, it is possible to quantify the increase in diffusive properties resulting from the chemical alterations due to external solutions. Tests are still ongoing in this program.

\section{$\underline{\text { CBP Cementitious Material Mineral Phase Characterization }}$}

While extensive information is available on the solid phases and microstructure of ordinary Portland cement matrixes, only limited analogous information is available for the ternary mix designs (e.g., Portland cement with fly ash and granulated blast furnace slag). XRD and Neutron Diffraction evaluations are underway of the representative CBP grout wasteform formulation to directly identify and characterize major mineral phases. 


\section{CBP Papers and Abstracts}

The CBP Partners submitted many abstracts and papers in the Waste Management Symposia 2013 on various aspects of $\mathrm{CBP}$ research and modeling as described in this section.

a. "The Cementitious Barriers Partnership (CBP) Software Toolbox Capabilities in Assessing the Degradation of Cementitious Barriers", Waste Management 2013 -13487

The Cementitious Barriers Partnership (CBP) Project is a multi-disciplinary, multi- institutional collaboration supported by the U.S. Department of Energy (US DOE) Office of Tank Waste Management. The CBP program has developed a set of integrated tools (based on state-ofthe-art models and leaching test methods) that help improve understanding and predictions of the long-term structural, hydraulic and chemical performance of cementitious barriers used in nuclear applications. Tools selected for and developed under this program have been used to evaluate and predict the behavior of cementitious barriers used in near- surface engineered waste disposal systems for periods of performance up to or longer than 100 years for operating facilities and longer than 1000 years for waste disposal.

The CBP Software Toolbox is and will continue to produce tangible benefits to the working DOE Performance Assessment (PA) community. A review of prior DOE PAs has provided a list of potential opportunities for improving cementitious barrier performance predictions through the use of the CBP software tools. These opportunities include:

1) Impact of atmospheric exposure to concrete and grout before closure, such as accelerated slag and Tc-99 oxidation,

2) Prediction of changes in $\mathrm{Kd} /$ mobility as a function of time that result from changing $\mathrm{pH}$ and redox conditions,

3) Concrete degradation from rebar corrosion due to carbonation,

4) Early-age cracking from drying and/or thermal shrinkage and

5) Degradation due to sulfate attack.

The CBP has already had opportunity to provide near-term, tangible support to ongoing DOE-EM PAs such as the Savannah River Saltstone Disposal Facility (SDF) by providing a sulfate attack analysis that predicts the extent and damage that sulfate ingress will have on the concrete vaults over extended time (i.e., > 1000 years). This analysis is one of the many technical opportunities in cementitious barrier performance that can be addressed by the DOE-EM sponsored CBP software tools. Modification of the existing tools can provide a plethora of opportunities to bring defense in depth in prediction of the performance of cementitious barriers over time. 


\section{b. "CBP Phase I Code Integration", Waste Management Paper 11446}

The CBP simulation tools are being used to evaluate and predict the behavior of cementitious barriers used in near surface engineered waste disposal systems including wasteforms, containment structures, entombments, and environmental remediation. These cementitious materials are exposed to dynamic environmental conditions that cause changes in material properties via (i) aging, (ii) chloride attack, (iii) sulfate attack, (iv) carbonation, (v) oxidation, and (vi) primary constituent leaching. A set of state-of-the-art software tools has been selected as a starting point to capture these important aging and degradation phenomena.

Integration of existing software developed by the CBP partner organizations was determined to be the quickest method of meeting the CBP goal of providing a computational tool that improves the prediction of the long-term behavior of cementitious materials. The CBP partner codes selected for the Phase I integration effort were:

- LeachXS ${ }^{\mathrm{TM}} / \mathrm{ORCHESTRA}$ developed by the Energy Research Centre of the Netherlands (ECN) (ECN 2007, Meeussen 2003) and

- $\quad$ STADIUM $^{\circledR}$ developed by SIMCO Technologies, Inc. (SIMCO 2008).

These partner codes were selected based on their maturity and ability to address the problems outlined above. The GoldSim Monte Carlo simulation program (GTG 2010a, GTG 2010b) was chosen as the code integration platform (Brown \& Flach 2009b). GoldSim (current Version 10.5) is a Windows based graphical object-oriented computer program that provides a flexible environment for model development (Brown \& Flach 2009b). The linking of GoldSim to external codes has previously been successfully demonstrated (Eary 2007, Mattie et al. 2007). GoldSim is capable of performing deterministic and probabilistic simulations and of modeling radioactive decay and constituent transport.

As part of the CBP project, a general Dynamic Link Library (DLL) interface was developed to link GoldSim with external codes (Smith III et al. 2010). The DLL uses a list of code inputs provided by GoldSim to create an input file for the external application, runs the external code, and returns a list of outputs (read from files created by the external application) back to GoldSim. In this way GoldSim provides: 1) a unified user interface to the applications, 2) the capability of coupling selected codes in a synergistic manner, and 3) the capability of performing probabilistic uncertainty analysis with the codes. GoldSim is made available by the GoldSim Technology Group as a free "Player" version that allows running but not editing GoldSim models. The player version makes the software readily available to a wider community of users that would wish to use the CBP application but do not have a license for GoldSim. 
c. "Cementitious Barriers Partnership (CBP): Training and Release of CBP Toolbox Software, Version 1.0", Waste Management 2013 - 13480

CBP software tools were made available to selected DOE Office of Environmental Management and other users for training and evaluation based on a set of important degradation scenarios, including sulfate ingress/attack and carbonation of cementitious materials. The tools that were presented at two-day training workshops held at NIST, Savannah River, and Hanford included LeachXS ${ }^{\text {тM }} /$ ORCHESTRA, STADIUM $^{\circledR}$, new U.S. Environmental Protection Agency leaching test methods based on the Leaching Environmental Assessment Framework (LEAF), and a CBP-developed GoldSim Dashboard interface. Collectively these components form the CBP Software Toolbox. The CBP Dashboard uses a custom Dynamic-link library developed by CBP to couple to the LeachXS ${ }^{\mathrm{TM}} /$ ORCHESTRA and STADIUM $^{\circledR}$ codes to simulate reactive transport and degradation in cementitious materials for selected performance assessment scenarios. The first day of the workshop introduced participants to the software components via presentation materials, and the second day included hands-on tutorial exercises followed by discussions of enhancements desired by participants. Tools were revised based on feedback obtained during the workshops; the resulting improved CBP Software Toolbox, including evaluation versions of STADIUM ${ }^{\circledR}$ and LeachXS ${ }^{\text {TM }}$ /ORCHESTRA, has been made available to workshop and selected other participants for further assessment.

d. "Cementitious Barriers Partnership (CBP): Using the CBP Software Toolbox to Simulate Sulfate Attack and Carbonation of Concrete Structures", Waste Management 2013 $\underline{13481}$

The CBP project has developed a set of integrated modeling tools and leaching test methods to help improve understanding and prediction of the long-term hydraulic and chemical performance of cementitious materials used in nuclear applications. State-of-the-art modeling tools, including LeachXS ${ }^{\text {TM }}$ /ORCHESTRA and STADIUM ${ }^{\circledR}$, were selected for their demonstrated abilities to simulate reactive transport and degradation in cementitious materials. The new U.S. Environmental Protection Agency leaching test methods based on the Leaching Environmental Assessment Framework (LEAF), now adopted as part of the SW-846 RCRA methods, have been used to help make the link between model and experiment.

Although each of the CBP tools has demonstrated utility as a standalone product, coupling the models over relevant spatial and temporal solution domains should provide more accurate predictions of cementitious materials behavior over relevant periods of performance. The LeachXS ${ }^{\text {TM }} /$ ORCHESTRA and STADIUM ${ }^{\circledR}$ models were first linked to the GoldSim Monte Carlo simulator to better characterize model uncertainties and as a means to coupling the models. Two important degradation scenarios were selected for initial demonstration: sulfate ingress / attack and carbonation of cementitious materials. When sufficient sulfate is present in the pore 
solution external to a concrete barrier, sulfate can diffuse into the concrete, react with the concrete solid phases, and cause cracking that significantly changes the transport and structural properties of the concrete. The penetration of gaseous carbon dioxide within partially saturated concrete usually initiates a series of carbonation reactions with both dissolved ions and the hydrated cement paste. The carbonation process itself does not have a negative effect, per se, on the paste physical properties and can even result in reduced porosity and can help form a protective layer at the surface of concrete. However, carbonation has been shown to increase leaching of some constituents and can potentially have a detrimental effect on reinforced concrete structures by destroying the passive layer around embedded steel (e.g. rebar) and accelerating corrosion, which are important processes related to high-level waste tank integrity and closure evaluations. The use of the CBP Software Toolbox to simulate these important degradation phenomena for both concrete vaults and high-level waste tanks are demonstrated in this paper.

\section{e. "A Dual Regime Reactive Transport Model for Simulation of High Level Waste Tank Closure} Scenarios", Waste Management 2013-13375

A numerical simulation framework is presented in this paper for estimating evolution of $\mathrm{pH}$ and release of major species from grout within high-level waste tanks after closure. This model was developed as part of the Cementitious Barriers Partnership. The reactive transport model consists of two parts - (1) transport of species, and (2) chemical reactions. The closure grout can be assumed to have varying extents of cracking and composition for performance assessment purposes. The partially or completely degraded grouted tank is idealized as a dual regime system comprising of a mobile region with cracks and macropores, and an immobile/stagnant region comprising of the solid matrix with micropores. The transport profiles of the species are calculated by incorporating advection of species through the mobile region, diffusion of species through the immobile/stagnant region, and exchange of species between the mobile and immobile regions. A geochemical speciation code in conjunction with the $\mathrm{pH}$ dependent test data for a grout material is used to obtain a mineral set that best describes the trends in the test data of the major species. The dual regime reactive transport model predictions are compared with the release data from an up-flow column percolation test. The coupled model is then used to assess effects of crack state of the structure, rate and composition of the infiltrating water on the $\mathrm{pH}$ evolution at the grout-waste interface. The coupled reactive transport model developed in this work can be used as part of the performance assessment process for evaluating potential risks from leaching of a cracked tank containing elements of human health and environmental concern. 


\section{CBP Future Activities (FY13)}

In FY13, CBP partners plan to concentrate on developing a new software module(s) to define the flow and transport of contaminants through cracks also referred to as fractured media. Experimental programs are underway to provide the necessary data to develop and calibrate this software module. Demonstration cases will be developed to provide examples for evaluating chemical evolution and radionuclide leaching under high level waste tank closure scenarios.

Also in FY2013 the CBP plans to a) refine the CBP Software Toolbox based on beta-user feedback and release an updated version to the DOE-EM Performance Assessment community, including an updated user manual, b) continue development of carbonation and fractured flow software modules, and c) continue material characterization and model validation experiments. A lack of funding for NIST and SIMCO for the remainder of FY2012 and FY2013 will preclude THAMES model development, and delay or disrupt model validation experiments at SIMCO 


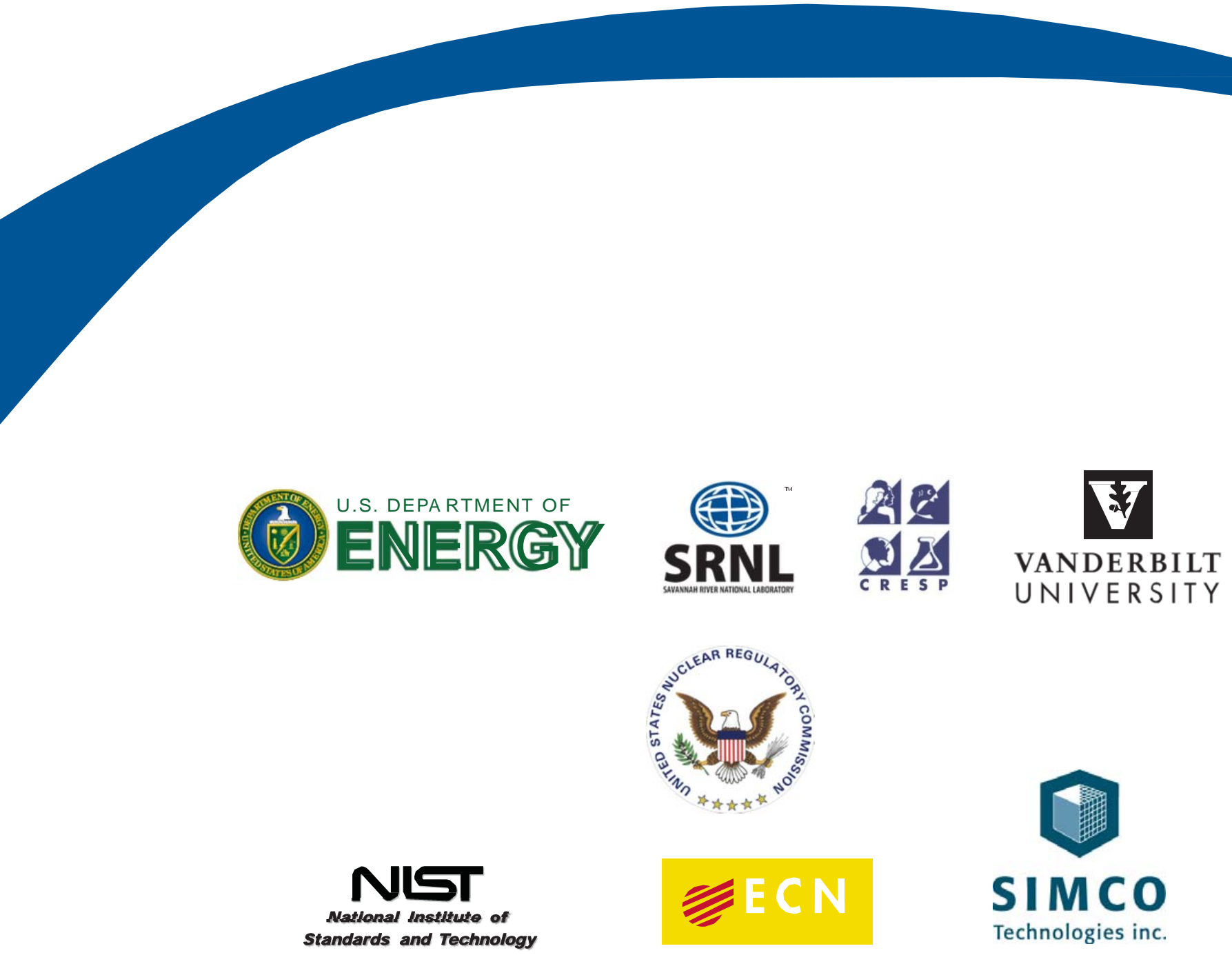

